\title{
EXPERIMENTAL ASSESSMENT OF TEXTILE REINFORCED SPRAYED MORTAR STRENGTHENING SYSTEM FOR BRICKWORK WALLETTES
}

\author{
Ernest Bernat-Maso ${ }^{a^{*}}$, Christian Escrig ${ }^{\mathrm{a}}$,Chrysl A. Aranha ${ }^{\mathrm{b}}$, Lluís Gil ${ }^{\mathrm{a}}$ \\ ${ }^{\mathrm{a}}$ Department of Strength of Materials and Engineering Structures \\ Technical University of Catalonia.Colom 11. 08222Terrassa, Spain \\ ${ }^{\mathrm{b}}$ ISISE, Department of Civil Engineering \\ University of Minho, Guimares, Portugal
}

\begin{abstract}
This work explores the feasibility of strengthening masonry with Textile Reinforced Mortar (TRM) by projecting it to save application time. Nineteen tests on masonry samples strengthened with TRM have been carried out to assess this new application method. Different mortars and fibre grids were considered for studying their influence and applicability with this new technique. Three points bending tests have been performed on the specimens to compare the flexural strength between cases with manually applied mortar (TRM) and sprayed application (TRSM) of the mortar layer. It was noticed that the strengthening mortar has a significant influence on the failure mode. Results show a remarkable (between 2 and 6 times more) productivity increase when using TRSM and a load-bearing capacity rise for the cases with larger grid spacing and projectable mortar when using TRSM instead of TRM. Greater ductility values were also observed for the TRSM cases in comparison with the analogue TRM cases (same grid and mortar).
\end{abstract}

\section{KEYWORDS}

Textile Reinforced Mortar, Strengthening, Masonry, Experimental test, Application Technique

${ }^{*}$ Corresponding author:

Tel.: +34 937398728; fax: 937398994

e-mail address: ernest.bernat@upc.edu 


\section{INTRODUCTION}

Unreinforced masonry has been extensively used as a construction material in the building industry, especially for residential buildings. Most of these buildings are still in service and some require strengthening interventions in order to adapt the structure for a new use or to fulfil the requirements of current structural codes. The low shear and tensile strength of this material are the limiting properties for this adaptation. Unreinforced masonry structures are designed to withstand compressive loads and strengthening them is necessary to bear tensile forces.

Among the innovative masonry strengthening methods studied by other research, it is worth mentioning the Fibre Reinforced Polymers (FRP) because of their wide use. This solution has proven to be effective on concrete structures but showed significant drawbacks when applied on masonry because of the use of organic resins as part of the FRP strengthening [1]. The most important issues are the hygrometric and mechanical incompatibilities between the masonry and the resin, the loss of strength of epoxy resins above the glass transition temperature and the toxicity of the materials. This situation led to the proposal of several alternatives. The most significant ones are the Engineering Cementitious Concrete (ECC) presented by Maalej et al. [2] who strengthened masonry panels against out-of-plane loads with promising results (blast protection) and the Textile Reinforced Mortar (TRM) initially developed for strengthening concrete structures (see $[3,4]$ ) but successfully adapted for its application on masonry (see $[5,6])$. Nowadays, TRM is the most studied strengthening solution for masonry but as the application technique is by hand and is time-consuming, the system needs to be improved in order to become a competitive alternative. It has to be highlighted that TRM has been deeply analysed as a strengthening solution: Ortlepp et al. [7] presented a methodology for the mechanical characterisation of TRM, Harajli et al. [8] showed its performance against cyclic bending loads and Papanicolau et al. [6] compared the TRM system with the FRP solution. For all these cases the application of TRM was by hand.

To improve the TRM strengthening system, the projection of concrete (shotcrete) was considered as the technological base to develop an industrialized hybrid method consisting of placing a textile grid embedded inside a layer of projected concrete. This technique was efficiently used for the first time when strengthening a concrete structure at the University of Applied Sciences in Schweinfurt, Germany [9]. However, adapting this system for masonry structures has not been considered yet and the use of mortar instead of concrete needs to be studied too.

For this reason, the original work presented herein is focused on comparing the performance of manual and mechanical application of TRM. Several masonry samples have been built and manually strengthened with different commercial TRM systems, whereas other samples have been strengthened by projecting a plastering mortar on different fibre grids previously attached to the masonry surface. This system, which could be called Textile Reinforced Sprayed Mortar (TRSM), is fully described. It has to be remarked that the mortars developed to be applied in TRM strengthening systems cannot be projected because of the size of the sand. Hence, a plastering mortar (with lower bonding, compressive and flexural strength) was used for projecting purposes. 
All samples were tested under bending and the influence of different strengthening parameters (grid geometry and material, number of grids and strengthening of one or two sides) has been analysed for the TRSM cases. In addition, some of the TRSM samples have been used for performing a comparative study with TRM cases (manual application).

The possibility of adapting the existing commercial TRM solutions to be applied by projection is discussed and the comparison between the two application modes (TRM and TRSM) is presented showing that the type of the mortar is an important variable to be taken into account in the analysis.

The economic analysis of implementing the TRSM technology is out of the scope of the present paper which is focused on the technical aspects of this new way of applying the TRM strengthening.

To sum up, the main aim of the present work is to prove the feasibility of using TRSM as a suitable and quicker strengthening method for masonry structures in comparison with the original TRM solution.

\section{PROCEDURE}

To achieve the main aim of the research three experimental groups were defined. The strengthened samples are summarised in Table 1. The codification of these samples was ABC$X Y-Z$ where $A$ represents the application process of the TRM, $M$ for hand application and $S$ for sprayed application; the second letter represents the material the strengthening grid was made of, $G$ for glass, $C$ for carbon, $S$ for steel and $B$ for basalt; $C$ represents the type of mortar, $M$ for a cementitious-based mortar which is specifically designed for TRM, $R$ for a lime-based mortar which is also specifically designed for TRM application, $X$ for a pozzolana-based mortar also designed for TRM systems and $O$ for a projectable plastering mortar; the number $X$ represents the number of strengthened sides and $Y$ the number of fibre grids installed per side; finally, the number $Z$ shows the repetition order of analogue samples.

- In the first group three masonry specimens were fabricated as control samples for comparison purposes with the rest of the tests. They were masonry prisms stacked with ten bricks each. It was considered unnecessary to include the data acquired from these tests in Table 1 because the specimens were unreinforced and thus, failed under their own weight when placed in horizontal position.

- The second group consisted of nine specimens strengthened with Textile Reinforced Mortar (TRM) applied by hand. The studied parameters by comparing them might be the type of strengthening mortar and the fibre grid material. The mortars used for these cases were commercial mortars only. Each one of these mortars has been specifically designed to work with a specific textile (material and fibre grid geometry). These specimens consisted of masonry prisms of ten bricks each (except one case of nine bricks, labelled as MGR-11-1 in Table 1).

- The third group of samples was fabricated and tested in order to analyse the feasibility of the Textile Reinforced Sprayed Mortar (TRSM) system and to compare its performance with that obtained using TRM. For this part of the project, ten masonry 
specimens made by stacking nine bricks each in a prism were fabricated. The mortar used for embedding the fibre grid in it was developed for plastering works in contrast with the mortars of the second group. Hence, this fact is also considered as a study variable. Summarising, the parameters studied with the samples of this group were the type of textile grid, the number of layers of reinforcement and the number of reinforced sides.

\subsection{Properties of component materials}

To construct the specimens, solid clay bricks of size $280 \mathrm{~mm} \times 132 \mathrm{~mm} \times 45 \mathrm{~mm}$ were used. The water absorption capacity of the bricks taken in the dry and wet (immersed 1 minute prior) conditions were determined based on the guidelines given by EN 772-11:2000. The values were found to be $1.46 \mathrm{mg} / \mathrm{mm}^{2} \cdot \min$ and $0.65 \mathrm{mg} / \mathrm{mm}^{2} \cdot \min$ respectively.

The main characteristics of the used mortars are summarised in Table 2. The tests to measure the compressive and flexural strength were performed according EN 1015-11:1999/A1:2006. The values of the adhesion strength have been provided by the manufacturers of the mortars who tested them according with EN 1015-12. In total, five mortars were considered: one for the masonry joints and four to be used as a part of the TRM strengthening system:

- The mortar used for the joints of the masonry specimens is commercially classified as grade M7.5 although the compressive strength experimentally obtained is lower (see Table 2).

- A Portland cement based mortar, designated as $M$, which is a bi-component mortar characterised by its cementitious base and its high ductility.

- A lime based mortar, designated as $R$, which is also a bi-component mortar. this one has been pre-blended and in addition to hydraulic lime, eco-pozzolans and natural sand, contains special additives and synthetic polymers. $R$ mortar is categorized as M15 masonry-type mortar according to European standards.

- A pozzolana based mortar, designated as $X$, which is a mono-component mortar specially designed for bonding on masonry substrates.

- A plastering mortar, designated as $O$, which is a dry mix of cement, lime and chemical additives. This one is classified as an industrial mortar plaster / render according to European Standard EN 998-1. O mortar is specifically designed to be used as a projection mortar. Hence, it has a grain size of less than $1.6 \mathrm{~mm}$.

Mortars $M, R$ and $X$ have been specially developed to work with the corresponding particular textile grids. Conversely, the mortar that was used for spraying, $O$, was selected based on its shotcreting capability. Hence, the adhesion strength of the $O$ mortar is less than a half of the adhesion strength of the other mortars $(M, R$ and $X)$. Observing Table 2 it is noted that the mortar with the best adhesion performance among the ones used is the $M$ mortar.

The grids used were commercial textile grids made of fibres of basalt, carbon, glass and steel. According with the properties from the data sheets of the materials (see Table 3), the steel grids were the strongest and were the only ones with the fibres placed unidirectionally. The mesh size of the glass textile grid was the largest and that of steel was the smallest. The basalt grids were the most ductile with the larger ultimate elongation. The shape of the fibre grids is 
shown in Figure 1. It has to be reminded that the steel grid is unidirectional (the steel wires are horizontal in Figure 1) and the crossing lines observed in Figure 1 are thermo-welded plastic wires used to maintain the correct spacing and position of the steel wires.

\subsection{Application of the reinforcing mortar overlay}

Samples designated as MGM, MGR and MGX in Table 1 were air cured at indoor conditions for 21,44 and 51 days respectively before strengthening them whereas samples with $O$ mortar were covered and cured at outdoors conditions for 51 days before applying the strengthening system. Different curing durations before strengthening were due to planning restrictions and facilities availability. Nevertheless, it was always assured that the samples were at least 21 days old before strengthen them.

To begin with the manual strengthening procedure, the specimens were cleaned and the masonry surfaces which were going to have the TRM applied were wetted. These surfaces should be moist before applying the TRM to improve the adhesion performance of the strengthening mortar. Thus, water was poured onto the corresponding surfaces. This initial preparation was followed by the application of a layer of mortar of approximately $6 \mathrm{~mm}$ thickness using a flat metal trowel. While the mortar was still in the fresh state, the textile grid was appropriately positioned (with fibres vertically oriented) and incorporated into the mortar by flat pressing. Once the grid had been embedded into the mortar, a final layer of the mortar was applied and the surface was trowelled to produce a smooth appearance. The thickness of the second layer of mortar was about $4 \mathrm{~mm}$. The procedure for application of TRM is similar to the one carried out by Papanicolaou et al[1] and is graphically presented in Figure 2 .

In the third group of the research, three of the specimens (MSO-11-1, MGO-11-1 and MCO-111 , see Table 1) were reinforced with TRM manually applied following the same procedure as described above but using $O$ mortar for all these cases. For the specimens that were reinforced with TRSM, the mesh was initially placed in position leaving a gap between it and the masonry surface. Nuts were used like spacers and to attach the textile onto the masonry surface. Firstly, these nuts were glued to each corner of the grid and two more nuts were placed in the middle position of the longitudinal edges of the grid (the spacing between nuts was about $25 \mathrm{~cm}$ ). Then, the opposite side of the nuts was glued onto the masonry surface resulting with the grid attached to the masonry sample with a gap around $4 \mathrm{~mm}$ (the thickness of the nuts). The next step, performed after the glue dried, was wetting the surface as previously described for TRM strengthening. Finally, the $O$ mortar was sprayed on the surface of the specimens. The nozzle of the shotcreting machine was held perpendicular to the masonry surface and at about $50 \mathrm{~cm}$ away. The mortar was sprayed along the sides of the specimens first and then the interior was sprayed from down upwards until the entire surface was covered by a layer of sprayed mortar. The process of applying TRSM is graphically summarised in Figure 3.

To determine the influence of the number of strengthening fibre grids on the load-bearing capacity, two of the specimens were reinforced with two fibre grids (SBO-12-1 and SGO-12-1 as summarised in Table 1). In these cases, the strengthening procedure began as previously described for TRSM, but after the first layer of mortar was sprayed and it was still in a fresh state, the second textile grid was positioned and lightly pressed with a trowel onto the mortar. 
Finally, another layer of mortar was sprayed. Hence, the application of the second fibre grid was manual in the current research.

Although the surfaces of the specimens sprayed with mortar was uneven, trowelling was not carried out so as not to disturb the impaction bond between the sprayed mortar and masonry substrate. The shotcreting time for all the seven specimens, including two specimens with bilayered reinforcement and one specimen with reinforcement on either side, was less than two minutes. This time includes the mixing of the mortar which is continuously carried out by the projecting equipment. The procedure to bond the nuts on the grids lasted around 5 minutes and bonding them to the specimens required approximately 15 minutes. On completion, the samples reinforced with TRSM were cured indoors for twenty-eight days before testing.

It is worth noticing that the time taken to apply the mortar of the three specimens with handily applied TRM was four minutes. To this time, the time for the manual mixing of the mortar should be added and it was around 10 minutes.

If taking into account only the mortar application, the productivity increase might be around six times. The manual application of the mortar for a single fibre grid lasted around 90 seconds and projecting the mortar on the same surface lasted less than 15 seconds. If considering the grid and mortar preparation process previous to the mortar application, a single fibre grid might be installed in approximately 280 seconds by hand and required approximately 130 seconds with the proposed procedure. It is even likely that the application time of TRSM would be reduced for larger areas because most of the time was spend at spraying the mortar on the edges of the samples which required more precision.

Once strengthened, the overlaying mortar was air cured at indoor conditions without covering them for 46, 28, 52 and 28 days respectively for MGM, MGR, MCX and $O$-mortar specimens. Different curing times are due to planning limitations and facilities availability. However, what should be highlighted is that all TRM-strengthened specimens cured by at least 28 days before testing them. Some of the differences are explained because the manual strengthening was applied on different weeks but the specimens were tested all together.

\subsection{Flexure test}

The specimens were subjected to three-points bending tests after 28 days of curing the mortar of the TRM at least. Two testing procedures were considered: the first one was used for the specimens of the second experimental group. An adaptation of this method (changing the free span) was considered for the specimens of the third group in order to ease the development of shear failure modes and prevent the debonding collapse. In particular, the shear failure was observed in only one case of the second group and it was expected that the strengthening system using $O$ mortar could develop debonding process not observed in previous researches which used commercial TRM solutions (see [10]). For this reason the span was adapted.

The unreinforced specimens (first group) failed when placing the samples in the test setup because the flexural strength of the masonry was not enough to withstand its self-weight. This was the expected response and it is useful to qualitatively highlight the effectiveness of the TRM strengthening system. Because of the experimentally observed low performance of the 
unreinforced masonry against out-of-plane loads (the samples collapsed in the testing position), no testing procedure was executed for these first three samples.

For the specimens that were tested, the measurement of the ultimate load and the deflection were the main variables that were obtained. The continuous data of the applied load and deflection at mid-span was used to obtain a value of the flexural toughness of the samples. This calculated variable is useful to assess the ductility of the failure process, the energy needed to crack the section in flexure and the remaining flexural strength of the cracked sample. The procedure and calculations were based on the Japanese standard [11] which was adapted to the current tests on strengthened masonry samples to make an allowance for the inclusion of the unloading branch of the response. Hence, a non-conventional application of the method presented in [11] is proposed herein. The used adaptation consisted of calculating the surface under the force versus mid-span deflection curve until the mid-span deflection reached $L / 100$ instead of $L / 150$ as recommended in [11] for fibre-reinforced concretes. $L$ is the span of the test. It is because the TRM-strengthening masonry is more deformable than the fibre-reinforced concrete.

\subsubsection{Second group procedure}

These tests included the samples designated as MGM, MGR and MCX in Table 1. The specimens were measured and photographed in their initial state. Next, they were laid such that their reinforced side would be subjected to tension and placed in the testing position. Specimens were supported on two cylindrical steel rods which defined a free span of $560 \mathrm{~mm}$ (except for the sample MGR-11-1 which had a free span of $450 \mathrm{~mm}$ in order to prevent debonding failure mode and ease the shear failure). Then, the samples were aligned with the supports and the line of action of the load. The load was applied using a distribution steel beam fixed to the mobile part of an electromechanical press (Suzpecar, force range 50kN). Two potentiometers (Waycon LWR-100) were placed below the specimen and set to measure the deflection at mid-span. The average value was computed during the data processing stage. The force, measured with a load cell of $50 \mathrm{kN}$ range, and the displacement of each potentiometer, were simultaneously recorded at $50 \mathrm{~Hz}$ by a data acquisition system (HBM MGCPlus). The load application was displacement-controlled at a fixed ratio of $5 \mathrm{~mm} / \mathrm{min}$. Once the maximum load was reached and the load-bearing capacity of the specimen fell below a certain limit (set at $1 \mathrm{kN}$ ), the test was stopped. Finally, the thickness of the TRM layer on the broken sample at the mid-span section was measured as well as the distance between the masonry surface and the grid. The number of rovings embedded into the mortar was also noted. All these geometric values are summarised in Table 1 . The test setup is presented in Figure 4.

\subsubsection{Third group procedure}

This batch was oriented to test the samples strengthened with $O$-mortar. For the third group of the experiment, the testing procedure was the same than the one explained in section 2.3.1 except for three changes. Firstly, an elastomeric material was placed above two plain supports which replace the steel rods to assure a more uniform contact with the specimen. Similarly, a sheet of thermocol was also placed below the loading beam to ensure the uniformity in the load distribution which was applied at the midspan. This practice was supported by the European standard ISO 14125 which allows the use of a "thin shim or a cushion like material 
between the loading member and the specimen in order to discourage failure of the compressive face of the specimen". This variation was aimed to assure a uniform contact is spite of the uneven surface of the TRSM surface.

The second change was that the number of potentiometers was increased to six. There was one extra sensor near each of the four ends, two centimetres from the supports. These were installed in order to measure the settling displacement caused by the deformation of the elastomeric pieces placed between the supports and the specimen. During the data processing, the values obtained for settling deformation were subtracted from the corresponding mid-span deflections. The test setup of this third group is shown in Figure 5.

Finally, the free span was $450 \mathrm{~mm}$ for the samples of the third group in contrast with the $560 \mathrm{~mm}$ of the first and second. The reduction of the free span was oriented to simplify the setting tasks and, more importantly, to adjust the samples' dimensions in order to increase the likelihood of observing failures due to shear and, specially, to reduce the debonding possibility usually associated with the out-of-plane deformation of the samples, and thus, with the bending moment. This adjustment was aimed to avoid the debonding failure which might be significant for the TRSM because the mortar was applied simply by projection and the $O$ mortar had the lower adhesion performance. Using the flexural moment as the comparison variable assures the comparability of both test configurations, although it has to be taken into account that reducing the span causes and increase of the influence of the shear phenomena.

For the particular case of the specimen that was reinforced on both the sides (SGO-21-1), the smoother surface was placed facing down.

\section{RESULTS}

As previously mentioned, no significant data was recorded for the three unreinforced samples as their flexural strength was not enough to bear even their self-weight. The bending moment at failure was estimated to be $0.02 \mathrm{kN} \cdot \mathrm{m}$ (based on the maximum bending moment at midspan assuming uniform load distribution). This expected result should be used only for qualitative comparison with the strengthened cases which bear far greater bending moments.

Figures 6-8 summarise the mechanical response of the samples strengthened with only one fibre grid. The relationship between the applied bending moment and the deflection at midspan is presented for each case. Figure 6 shows the mechanical response of the samples which were manually strengthened with one glass fibre grid embedded into a Portland based mortar (called $M$ ). These results, corresponding to three tests (MGM-111-1, MGM-11-2 and MGM-113 ), are presented together in an envelope (blue and red solid lines) to provide a more understandable graph. Thus, the solid lines in graphs of Figures 6-8 are not plots for single tests (except the upper one in Figure 8) but the lower or upper envelopes of the three tests for each series (MGM, MGR and MCX).

Figure 6 also includes the plot of the cases of manual and sprayed application of one glass grid embedded into the plastering mortar (called $O$ ), it is MGO-11-1 and SGO-11-1. Figure 7 is analogous to Figure 6, the only difference being that the envelopes correspond to the cases of the specimens (MGR-11-1, MGR-11-2 and MGR-11-3) that were manually strengthened with 
one glass fibre grid embedded in a lime based mortar (called $R$ ). Finally, Figure 8 focuses on carbon fibre strengthened cases, showing the envelopes of the hand application (MCX-11-1, MCX-11-2 and MCX-11-3) with pozzolanic mortar (called $X$ ) and the response for the manual and sprayed application of the plastering mortar (called $O$ ) with one carbon fibre grid corresponding to the samples MCO-11-1 and SCO-11-1 respectively.

Each graph in Figures 9-11 presents the results of one kind of fibre grid (glass, basalt and steel respectively) for the cases these grids were embedded in a layer of plastering mortar (called $O)$. These curves show the bending moment versus the mid-span displacement and characterise the mechanical response of the samples. The effect of placing 2 fibre grids embedded in one strengthening mortar layer is shown in the same plots (Figures 9-10). Finally, the effect of strengthening two sides of a sample (Figure 9) is also presented. All the graphics have the same scale in order to have a direct comparison.

Table 4 summarises the results of the experimental campaign. This table includes the value of the free span $(L)$, the maximum applied load $\left(F_{u}\right)$, the maximum bending moment at mid-span $\left(M_{u}\right)$ obtained as $M_{u}=F_{u} \cdot L / 4+M_{w} \cdot M_{w}$ is the bending moment associated with the self-weight, which is $24.4 \mathrm{Nm}$ for the samples with $560 \mathrm{~mm}$ of span and $16.5 \mathrm{Nm}$ for the samples with shorter span. However, the effect of the self-weigh has proven to be negligible for all cases because it represents less than $3 \%$ of the bending moment and the scattering of the masonry properties is known to be larger than this. Finally, the Table 4 shows the deflection at mid-span $\left(\delta_{u}\right)$ for the maximum loading state and the qualitative observed failure mode.

Four different failure modes where noticed in the presented experimental campaign. These are shown in Figure 12 and are described as:

a) Flexure collapse by the TRM tensile failure. Fibres broke when their maximum allowable elongation was reached.

b) Flexural cracking of the TRM and shear failure of the masonry. Transversal cracks appeared but fibres did not reach their elongation limit. Collapse occurred by sliding between the bricks and the masonry joint mortar.

c) Shear failure. Flexural cracks did not appear in the mortar surface and the TRM kept bonded to the masonry. A masonry joint slid and the specimen collapsed.

d) Delamination of the TRM after flexural cracking. The debonding process started from mid-span crack and spread to the support. The TRM underwent delamination so a part of the matrix stayed bonded to the masonry and another part debonded along with the fibre grid.

Finally, Table 4 and Figure 13 present the previously described measurement of the flexural toughness $\left(T E N_{\delta=L / 100}\right)$ for each specimen. These values were calculated using and adaptation of the method of the Japanese standard for fibre-reinforced concrete [11], as mentioned in section 2.3. This flexural toughness was used to analyse the post-cracking strength of the samples and the ductility of the collapse process. 


\section{COMPARISON AND DISCUSSION}

In this section, the influence of the type of mortar, the comparison between sprayed and handily application techniques, the effect of placing two fibre grids in one TRM layer or the effect of strengthening both sides of the samples are discussed.

To begin with, the discussion is focused on the influence of the type of mortar. The general trend is that the specimens which were strengthened with commercial TRM systems (it is a textile grid with the corresponding mortar developed specifically for being used with it) achieve greater bending capacity than specimens reinforced with handily application of plastering mortar $O$. It is observed by comparing the results of MGM and MGR samples with the results of the MGO test, and the results of the MCX samples with the result of the MCO test.

Observing Figures 6 and 7 it is noticed that the specimens strengthened with one glass fibre grid embedded in a Portland or lime-based mortar layer ( $M$ or $R$ mortars specifically developed for TRM) show, for the most unfavourable case (lower envelope, red line), greater strength than the best result for the specimens strengthened with one glass fibre grid embedded into the plastering mortar (with handily or sprayed application).

In addition, it is observed that the type of mortar might influence on the failure mode. Seeing Table 4 it is noticed that the two comparable (same span and application mode) samples with glass fibre grid (MGR-11-1 and MGO-11-1) show different failure modes. The sample strengthened with for-the-purpose-developed mortar, $R$, fails by flexure in contrast with the sample which used the plastering mortar, $O$, which collapsed by shear at a lower load than MGR-11-1 sample. This might be due to the different masonry properties of the samples associated to the typical scattering of this material. However, the mortar with lower strength values $(O)$ is associated with the lower load-bearing capacity, and that would need further research to distinguish if the mortar of the TRM strengthening systems might influence on the out-of-plane shear response of the strengthened masonry.

Looking at Figure 8, which includes the samples strengthened with one carbon fibre grid, the first thing to be remarked is the considerable distance between the envelopes (solid lines). In fact, this is the only case for which one envelope totally corresponds with a single test. It is the case of the upper (blue) envelope which corresponds with the test on the sample MCX-11-1 which showed a far greater strength than the other two comparable samples of the series. This difference might be caused by the adherence problems between the carbon fibre grid and the mortar $X$ which have been reported in previous works [10] and may affect samples MCX-11-1 and MCX-11-2.

Continuing with the analysis of the Figure 8 , it is noticed that the use of the for-the-purposedeveloped mortar (named $X$ ) leads to withstand slightly higher loads than in the cases of the samples reinforced with plastering $(O)$ mortar. Nevertheless, it has to be remarked that the maximum value of lower envelope (red solid line) of the cases using $X$ mortar approximately coincides with the maximum values of the curves representing the individual cases of the samples reinforced with $O$ mortar (MCO-11-1 and SCO-11-1). Thus, there seems to be little difference between of using $O$ and $X$ mortar. This might be cause by the adherence problem of some studied mortars with the carbon fibre grid (as mentioned in [10]). However, the 
scattering of the masonry properties and the variation of the span length suggest analysing these results carefully.

Observing Table 4 and focusing on the cases with a carbon fibre grid with $X$ and $O$ mortars, it is observed that the span length would explain a hypothetical change of the failure mode from flexure to shear. However, noticing that the shear force for cases MCX-11-2 and MCX-11-3 is close to the shear force for cases MCO-11-1 and SCO-11-1, it might be considered that the type of mortar actually affects the failure mode, changing from flexure for the $X$ mortar to debonding (see Figure 12) for the $O$ mortar. It is consistent with the fact that $O$ mortar is the one with lowest adhesion strength (see Table 2) among the ones used.

Regarding the flexural toughness (see Figure 13 and Table 4), it has been observed that the toughness of the specimens strengthened with full commercial TRM solutions (MGM, MGR and MGX cases) is in the same range of values than the toughness of the specimens strengthened with comparable TRSM systems (SGO and SCO), it means, using the same fibre grid but different mortar and application technique. These results, which should be analysed carefully because of the span differences between the compared tests, suggest that spraying mortar is not clearly associated with a lower mechanical performance of the strengthened structure.

Secondly, it is interesting to analyse the application technique as a defining variable of the structural response. It is worth remarking that samples reinforced with sprayed plastering mortar, $O$, and one fibre grid developed more bending capacity than the analogue specimens with handily application of the $O$ mortar (comparing MGO-11-1 with SGO-11-1, and MCO-11-1 with SCO-11-1). In contrast, the cases strengthened with steel grids (SSO-11-1 compared with MSO-11-1), were the only ones for which the flexural strength was higher for TRM than for the analogue TRSM. This can be observed in Table 4 and Figure 11. Studying these results altogether it has to be pointed out that the use of the projecting technique does not negatively affect the mechanical performance of the strengthening system except for the cases with such a little grid spacing (e.g. studied steel grids) that the projected mortar cannot penetrate the grid and thus, the adherence with the masonry is critic. This practical conclusion is supported by the evidence that the failure mode for all the cases with steel fibre is debonding.

It is also important to compare the samples with $O$ mortar to assess the influence of the TRSM technique on the flexural toughness. It has to be pointed out that the samples strengthened with sprayed mortar and glass or carbon fibre grids present higher toughness than the corresponding samples with manual application (comparing the results of samples MGO-11-1 with SGO-11-1 and MCO-11-1 with SCO-11-1). Like for the bending strength, the samples strengthened with a steel grid behave in the opposite way than those strengthened with carbon or glass fibre grids. The response of the steel grid strengthened samples is influenced by the little grid spacing (gap between rovings) which difficults the penetration of the sprayed mortar. Thus, if the grid spacing is enough to allow the sprayed mortar to pass, the TRSM solution achieves greater flexural toughness than the comparable TRM cases.

Following with the discussion, the possibility of using two fibre grids instead of one in order to improve the TRSM performance has to be analysed as a technical possibility. By comparing the results of the samples strengthened with only one fibre grid with the analogous ones but with 
two grids (comparing samples SBO-11-1 with SBO-12-1 and SGO-11-1 with SGO-12-1), it is noticed that the samples reinforced with two textile sheets withstand higher loads than the ones strengthened with just one textile sheet. In addition, the failure mode did not change when doubling the amount of fibre included into the strengthening layer (see Table 4). Analysing the data it is observed that the increase of the bending capacity was of $225 \%$ when placing basalt grids (SBO-12-1 respect SBO-11-1) and $80 \%$ in case of glass fibre grids (SGO-12-1 respect SGO-11-1). It has to be noted that the maximum theoretical improvement is $100 \%$ if comparing the cases of one and two fibre grids. In fact, previous research has noted that in general, doubling the amount of fibre does not duplicate the capacity of the strengthened structure (see [10]). This unexpected experimental result for the case of basalt grids might be explained by two causes: (a) placing two grids requires applying more mortar and the tensile strength of the extra mortar might provide the additional flexural strength; and (b) the scattering of the masonry properties might explain part of the difference.

Finally, for the cases of samples SGO-11-1 and SGO-21-1 (see Figure 9 ), it is observed that using TRSM on both faces of the specimen (SGO-21-1 case) does not change the mechanical response of the sample in comparison with strengthening only the tensile side of the sample (SGO-11-1).

To conclude with this section, it has to be remarked that all the cases provide a significant increase of the flexural strength in comparison with the non-strengthened cases which failed under self-weight load.

\section{CONCLUSIONS}

An experimental campaign to characterise the bending performance of masonry samples strengthened with Textile Reinforced Sprayed Mortar (TRSM) has been presented. Several variables have been analysed and their influence on the performance of TRSM has been studied.

Regarding the structural response, it has to be highlighted that the results of both TRM (Textile Reinforced Mortar) and TRSM samples show a great increase of their load bearing capacity in comparison with the unreinforced cases (which cannot withstand their own weight).

From the results obtained, the most relevant practical conclusions are as follows:

- The failure mode might depend on the mortar type. The typical flexure failure of the TRM commercial solutions which use for-the-purpose developed mortars can turn into a debonding failure. The debonding probability increase associated to the use of a plastering mortar with lower strength values is experimentally justified.

- The failure mode depends on the span and the shear becomes more influent, in comparison with the bending phenomena, when reducing the span. This fact explains the shear failure of some of the samples of the third experimental group which were tested with shorter span to avoid the debonding failure.

- The samples strengthened with the specifically developed mortars for TRM applications achieve greater load-bearing capacities than the ones strengthened with TRM using mortar for plastering purposes. 
- The spraying technique has no noticeable drawbacks in comparison with the hand application when compared under the same conditions (mortar type, fibre grids type and number of fibre grids). In fact, the flexural strength is usually higher if the grid spacing allows the mortar to pass and correctly bond the grid to the masonry surface.

- Spraying the mortar led to time saving in comparison with hand application.

- Placing a greater amount of strengthening fibre inside the TRSM layer leads to higher load-bearing capacity although some previous research show limited improvements. The influence of the additional mortar thickness has to be taken into account to explain the load-bearing capacity increase.

- The use of the TRSM solution on both sides of the samples (compression and tension sides) does not seem to improve the performance in comparison with the cases with the TRSM applied only on the tensile side.

- The samples strengthened with TRSM technique achieve higher toughness values than the corresponding TRM-strengthened cases.

In addition, it is also important to remark that the performance of the TRSM system (sprayed) is more sensitive to the grid geometry (spacing between rovings) and the application procedure than the case of the TRM (hand) because TRSM does not involve trowelling, which helps the penetration of the mortar through the spaces in the grid and increases bonding capacity. This trowelling process is, actually, an essential and time-consuming part of the hand application of TRM.

The application of TRM by spraying the mortar has proven to be time-efficient and the achieved structural performance has been noteworthy. However, the application procedure of TRSM showed some issues which have been observed. The less favourable aspects of this system in comparison with the TRM system are the larger amount of mortar consumption and the poor finishing of the strengthened surface.

Improving the collocation of the fibre grids by producing grids with the spacers pre-installed and ready to be mechanically attached to the support would improve the method. Achieving a balancing between the application time and the strengthening performance is an economical issue which would need further study in collaboration with rehabilitation practitioners. It is expected that the advantages of TRSM would be even more evident for large buildings where the time-saving might be even more than the estimated in this first approach.

Although the mortar used in TRSM was a rendering one instead of a specifically designed strengthening mortar, the experimental results show a significant increase of the load bearing capacity in comparison with the unreinforced samples. In addition, TRSM has shown even better results than the TRM for the cases of larger grid spacing when the same mortar and grid were used. Thus, it seems likely that improving the mortar performance to be projected would increase the TRSM system possibilities. As a further step, it would be necessary to develop a projectable mortar suitable to be part of a strengthening system to expand the TRSM application range.

Finally and taking into account the results on the whole, it has to be said that the technological feasibility of the TRSM has been demonstrated. 


\section{ACKNOWLEDGEMENTS}

This study has been partially carried out within the project "Uso de nuevosmateriales composites para el refuerzo y rehabilitación de estructuras de edificación y obra civil con criterios de sostenibilidad, TERREME", funded by the Spanish Ministry of Economics and Competitiveness, and project A1/038841/11 "Hormigónsostenible con fibrasvegetales", funded by the Spanish Ministry of Foreign Affairs and Cooperation, whose assistance is gratefully acknowledged.

The support of Ibermapei, S.A. and Ruredil, SpA is also acknowledged.

\section{REFERENCES}

[1] C.G. Papanicolaou, T.C. Triantafillou, M. Papathanasiou, K. Karlos, Textile reinforced mortar (TRM) versus FRP as strengthening material of URM walls: out-of-plane cyclic loading, Materials and Structures. 41 (2007) 143-157.

[2] M. Maalej, V.W.J. Lin, M.P. Nguyen, S.T. Quek, Engineered cementitious composites for effective strengthening of unreinforced masonry walls, Engineering Structures. 32 (2010) 2432-2439.

[3] A. Wiberg, Strengthening of Concrete Beams Using Cementitious Carbon Fibre Composites, Royal Institute of Technology of Sweden, 2003.

[4] T. Blanksvärd, B. Täljsten, Strengthening of concrete structures with cement based bonded composites, Journal of Nordic Concrete Research. 38 (2008) 133-154.

[5] L. Garmendia, J.T. San-José, D. García, P. Larrinaga, Rehabilitation of masonry arches with compatible advanced composite material, Construction and Building Materials. 25 (2011) 4374-4385.

[6] C. Papanicolaou, T. Triantafillou, M. Lekka, Externally bonded grids as strengthening and seismic retrofitting materials of masonry panels, Construction and Building Materials. 25 (2011) 504-514.

[7] R. Ortlepp, U. Hampel, M. Curbach, A new approach for evaluating bond capacity of TRC strengthening, Cement and Concrete Composites. 28 (2006) 589-597.

[8] J. Harajli, M.H., ELKhatib, H., Tomas San-Jose, Masonry Walls Strengthened Using Fibre Textile-Mortar System: Experimental Evaluation of Out-of-Plane Cyclic Response, in: CSHM-3, Ottawa-Gatineau, Canada, 2010: pp. 19-32.

[9] R. Ortlepp, M. Curbach, S. Weiland, Rehabilitation and strengthening of a hypar concrete shell by textile reinforced concrete, in: Y.K. Hsein, M.C. Limbachiya (Eds.), Excellence in Concrete Construction through Innovation, Taylor \& Francis, Kingston University, United Kingdom, 2008: p. 357. 
[10] E. Bernat, L. Gil, P. Roca, C. Escrig, Experimental and analytical study of \{TRM $\}$ strengthened brickwork walls under eccentric compressive loading, Construction and Building Materials. 44 (2013) 35-47.

[11] JSCE-SF4, JSCE-SF4. Method of tests for flexural strength and flexural toughness of steel fiber reinforced concrete, JSCE Japan Soci. Civil Eng. 3 (1984) 58-61. 


\section{Tables}

Table 1 Characterisation of the strengthened specimens

Table 2 Properties of the mortars, bricks and masonry

Table 3 Properties of the textile grids

Table 4 Summary of test results 


\begin{tabular}{cccccccc}
$\begin{array}{c}\text { Application } \\
\text { Method }\end{array}$ & Grid & $\begin{array}{c}\text { Overlaying } \\
\text { mortar }\end{array}$ & $\begin{array}{c}\text { No. of } \\
\text { reinforced } \\
\text { sides }\end{array}$ & $\begin{array}{c}\text { No. } \\
\text { of } \\
\text { grids } \\
\text { per } \\
\text { layer }\end{array}$ & $\begin{array}{c}\text { Mortar } \\
\text { thickness } \\
(\boldsymbol{m m})\end{array}$ & $\begin{array}{c}\text { No. of } \\
\text { rovings }\end{array}$ & Designation \\
\hline Hand & Glass & $\mathrm{M}$ & 1 & 1 & 10.5 & 10 & MGM-11-1 \\
\hline Hand & Glass & $\mathrm{M}$ & 1 & 1 & 9.0 & 10 & MGM-11-2 \\
\hline Hand & Glass & $\mathrm{M}$ & 1 & 1 & 11.5 & 11 & MGM-11-3 \\
\hline Hand & Glass & $\mathrm{R}$ & 1 & 1 & 11.0 & 10 & MGR-11-1 \\
\hline Hand & Glass & $\mathrm{R}$ & 1 & 1 & 13.5 & 10 & MGR-11-2 \\
\hline Hand & Glass & $\mathrm{R}$ & 1 & 1 & 10.5 & 11 & MGR-11-3 \\
\hline Hand & Carbon & $\mathrm{X}$ & 1 & 1 & 11.0 & 29 & MCX-11-1 \\
\hline Hand & Carbon & $\mathrm{X}$ & 1 & 1 & 10.0 & 29 & MCX-11-2 \\
\hline Hand & Carbon & $\mathrm{X}$ & 1 & 1 & 5.0 & 30 & MCX-11-3 \\
\hline Hand & Glass & $\mathrm{O}$ & 1 & 1 & 7.0 & 11 & MGO-11-1 \\
\hline Hand & Carbon & $\mathrm{O}$ & 1 & 1 & 1.0 & 27 & MCO-11-1 \\
\hline Hand & Steel & $\mathrm{O}$ & 1 & 1 & 6.0 & 42 & MSO-11-1 \\
\hline Sprayed & Glass & $\mathrm{O}$ & 1 & 1 & 2.5 & 11 & SGO-11-1 \\
\hline Sprayed & Carbon & $\mathrm{O}$ & 1 & 1 & 2.0 & 27 & SCO-11-1 \\
\hline Sprayed & Steel & $\mathrm{O}$ & 1 & 1 & 2.0 & 42 & SSO-11-1 \\
\hline Sprayed & Basalt & $\mathrm{O}$ & 1 & 1 & 0.5 & 17 & SBO-11-1 \\
\hline Sprayed & Basalt & $\mathrm{O}$ & 1 & 2 & 1.0 & 17 & SBO-12-1 \\
\hline Sprayed & Glass & $\mathrm{O}$ & 1 & 2 & 4.0 & 11 & SGO-12-1 \\
\hline Sprayed & Glass & $\mathrm{O}$ & 2 & 1 & 4.0 & 11 & SGO-21-1 \\
& & Table 1 Characterisation of the strengthened specimens & & \\
\hline & & & & & &
\end{tabular}

\begin{tabular}{|c|c|c|c|c|}
\hline \multicolumn{2}{|l|}{ Material } & $\begin{array}{c}\text { Compressive strength } \\
\text { (MPa) }\end{array}$ & $\begin{array}{l}\text { Flexural strength } \\
\text { (MPa) }\end{array}$ & $\begin{array}{l}\text { Adhesion strength* } \\
\text { (MPa) }\end{array}$ \\
\hline \multirow{4}{*}{$\begin{array}{l}\text { Mortar for } \\
\text { overlay }\end{array}$} & $M$ & $42.2(0.18)$ & $8.06(0.27)$ & 2 \\
\hline & $R$ & $14.5(0.08)$ & $6.57(0.03)$ & 0.8 \\
\hline & $x$ & $34.5(0.08)$ & $9.39(0.10)$ & 0.8 \\
\hline & 0 & $4.6(0.02)$ & $2.10(0.03)$ & 0.3 \\
\hline \multicolumn{2}{|c|}{ Mortar for joints } & $3.7(0.63)$ & $1.25(0.89)$ & --- \\
\hline \multicolumn{2}{|c|}{ Bricks } & $27.9(0.19)$ & $2.81(0.28)$ & --- \\
\hline \multicolumn{2}{|l|}{ Masonry } & $10.8(3.05)$ & $0.36(0.18)$ & --- \\
\hline
\end{tabular}

Table 2 Properties of the mortars, bricks and masonry 


\begin{tabular}{ccccc} 
Material type & Basalt & Carbon & Glass & Steel \\
\hline Designation & $\mathrm{B}$ & $\mathrm{C}$ & $\mathrm{G}$ & $\mathrm{S}$ \\
\hline Fibre orientation & Bi-directional & Bi-directional & Bi-directional & Unidirectional \\
\hline Grid spacing $(\mathrm{mm})$ & 10 & 10 & 25 & 5 \\
\hline Weight $\left(\mathrm{g} / \mathrm{m}^{2}\right)$ & 300 & 168 & 225 & 600 \\
\hline $\begin{array}{c}\text { Ultimate tensile strength } \\
(\mathrm{kN} / \mathrm{m})\end{array}$ & 92 & 160 & 45 & 230 \\
\hline Modulus of Elasticity $(\mathrm{GPa})$ & 95 & 240 & 90 & 190 \\
\hline \% Elongation & 3.15 & 1.8 & 3.0 & 1.6
\end{tabular}

Table 3 Properties of the textile grids

\begin{tabular}{ccccccc} 
Designation & $\boldsymbol{L}(\mathbf{m m})$ & $\boldsymbol{F}_{u}(\mathbf{k N})$ & $\boldsymbol{M}_{u}(\mathbf{k N} \cdot \boldsymbol{m})$ & $\boldsymbol{\delta}_{u}(\mathbf{m m})$ & Failure Mode & TEN $_{\delta=L / 100}(\boldsymbol{J})$ \\
\hline MGM-11-1 & 560 & 10.27 & 1.46 & 5.06 & Flexure & 38.90 \\
\hline MGM-11-2 & 560 & 11.10 & 1.58 & 5.18 & Flexure & 32.20 \\
\hline MGM-11-3 & 560 & 12.95 & 1.84 & 3.84 & Flexure & 46.81 \\
\hline MGR-11-1 & 450 & 13.03 & 1.48 & 4.87 & Flexure & 22.93 \\
\hline MGR-11-2 & 560 & 9.37 & 1.34 & 5.66 & Flexure & 21.27 \\
\hline MGR-11-3 & 560 & 10.98 & 1.56 & 5.31 & Flexure & 34.18 \\
\hline MCX-11-1 & 560 & 21.67 & 3.06 & 2.73 & Flexure -> Shear & 51.93 \\
\hline MCX-11-2 & 560 & 7.03 & 1.01 & 1.52 & Flexure & 16.57 \\
\hline MCX-11-3 & 560 & 7.13 & 1.02 & 2.82 & Flexure & 19.17 \\
\hline MGO-11-1 & 450 & 6.67 & 0.77 & 5.56 & Shear & 25.43 \\
\hline MCO-11-1 & 450 & 6.38 & 0.73 & 0.23 & Debonding & 18.34 \\
\hline MSO-11-1 & 450 & 26.66 & 3.02 & 2.03 & Debonding & 92.52 \\
\hline SGO-11-1 & 450 & 8.37 & 0.96 & 2.97 & Flexure -> Shear & 33.89 \\
\hline SCO-11-1 & 450 & 6.84 & 0.79 & 0.19 & Debonding & 23.57 \\
\hline SSO-11-1 & 450 & 18.22 & 2.07 & 0.61 & Debonding & 72.16 \\
\hline SBO-11-1 & 450 & 4.65 & 0.54 & 1.00 & Flexure & 14.19 \\
\hline SBO-12-1 & 450 & 15.06 & 1.71 & 2.23 & Flexure & 52.88 \\
\hline SGO-12-1 & 450 & 15.06 & 1.71 & 2.32 & Flexure $>$ Shear & $22.28^{(1)}$ \\
\hline SGO-21-1 & 450 & 10.04 & 1.15 & 1.57 & Flexure -> Shear & 33.19 \\
\hline
\end{tabular}

(1) Test did not reach L/100 mid-span displacement 


\section{Figures}

Figure 1 Fibre grids

Figure 2 TRM hand application procedure

Figure 3 TRSM application procedure

Figure 4 Test setup for the second group of the experimental campaign

Figure 5 Test setup for the third group of the experimental campaign

Figure 6 Bending moment - Mid-span displacement: upper and lower envelope for specimens of the MGM-11 series and data for the 3rd group specimens reinforced with only one glass fibre sheet

Figure 7 Bending moment - Mid-span displacement: upper and lower envelope for specimens of the MGR-11 series and data for the 3rd group specimens reinforced with only one glass fibre sheet

Figure 8 Bending moment - Mid-span displacement: upper and lower envelope for specimens of the MCX-11 series and data for the 3rd group specimens reinforced with only one carbon fibre sheet

Figure 9 Bending moment - Mid-span displacement curves for 3rd group specimens strengthened with glass fibre grids

Figure 10 Bending moment - Mid-span displacement curves for 3rd group specimens strengthened with basalt fibre grids

Figure 11 Bending moment - Mid-span displacement curves for 3rd group specimens strengthened with steel fibre

Figure 12 Failure of the specimens tested

Figure 13 Absorbed energy at L/100 mid-span displacement 


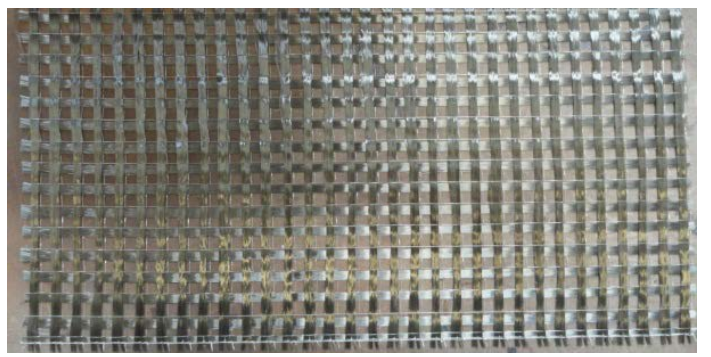

Basalt

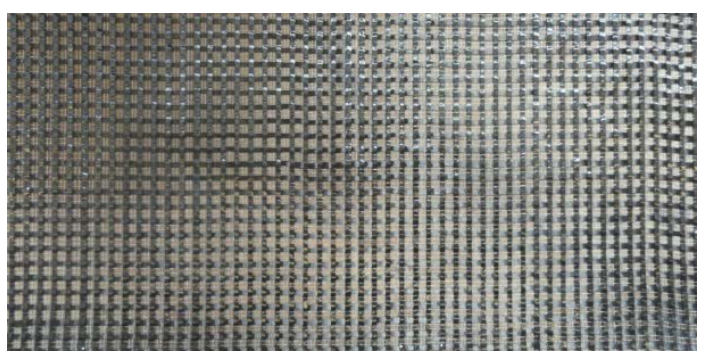

Carbon

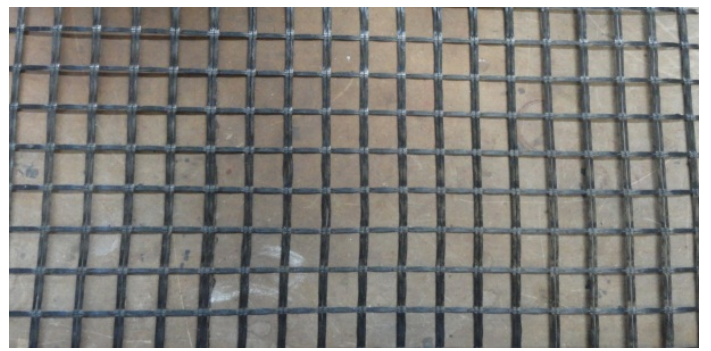

Glass

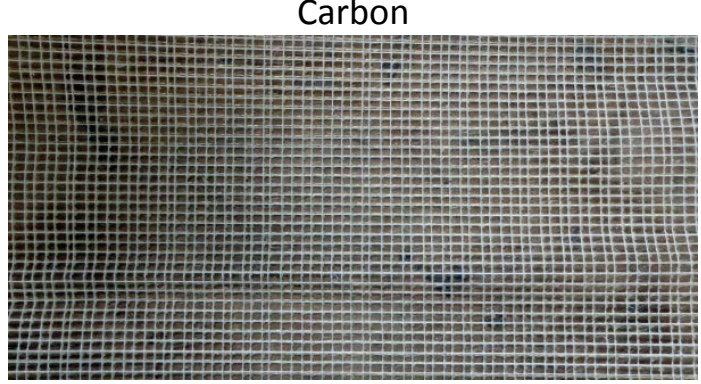

Steel

Figure 1 Fibre grids

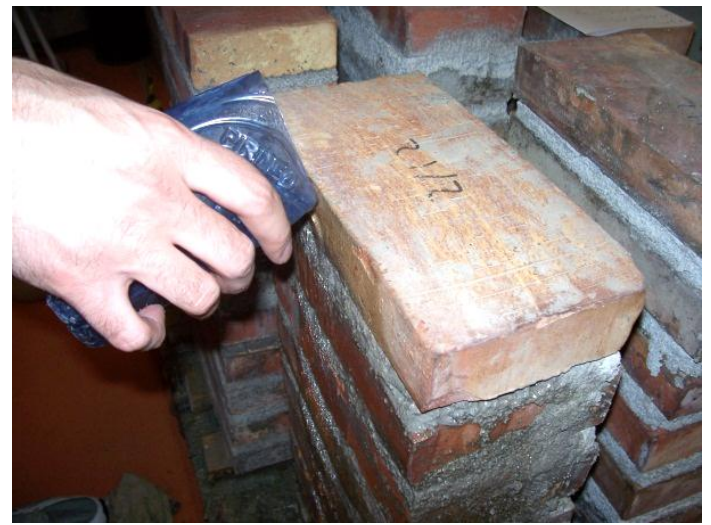

a) Wetting the specimen

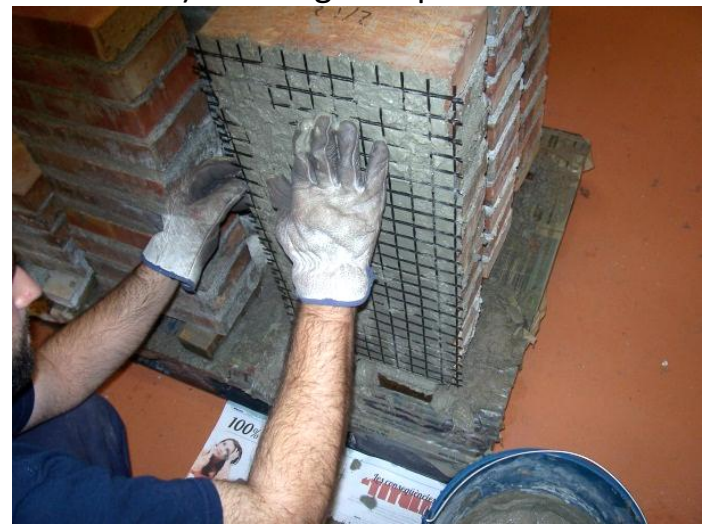

c) Laying the grid in the mortar

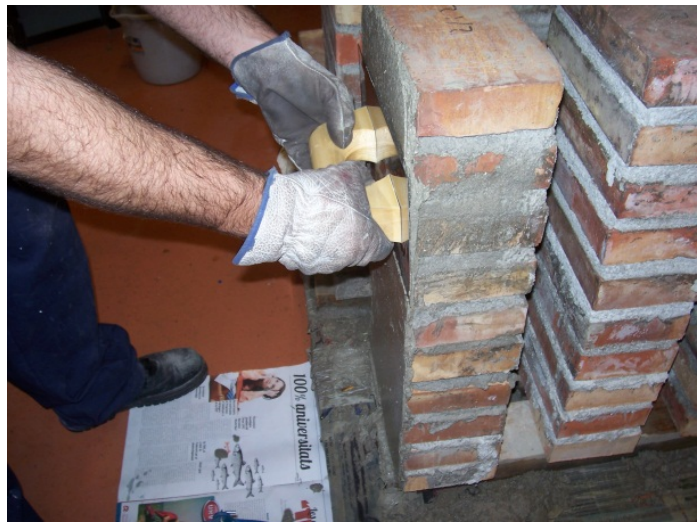

b) Applying the first mortar layer

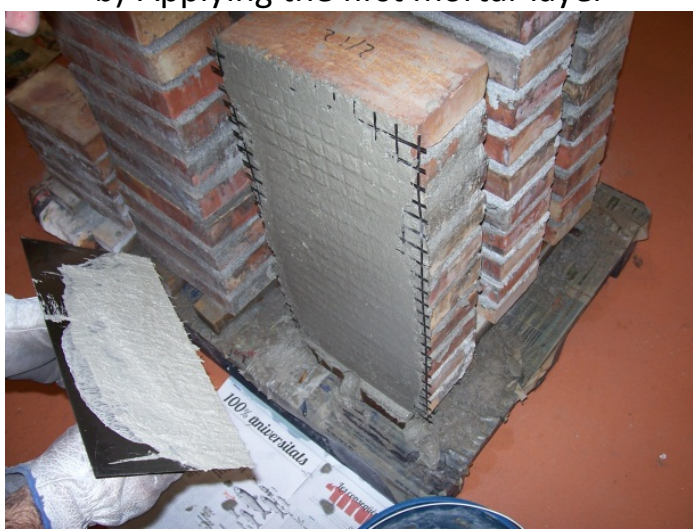

d) Applying the final mortar layer

Figure 2 TRM hand application procedure 


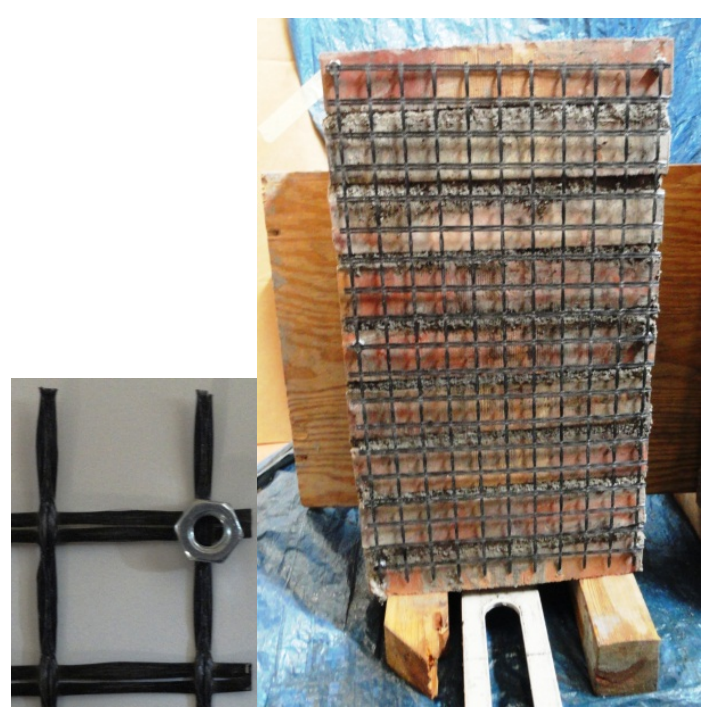

a) Fixing the textile grid

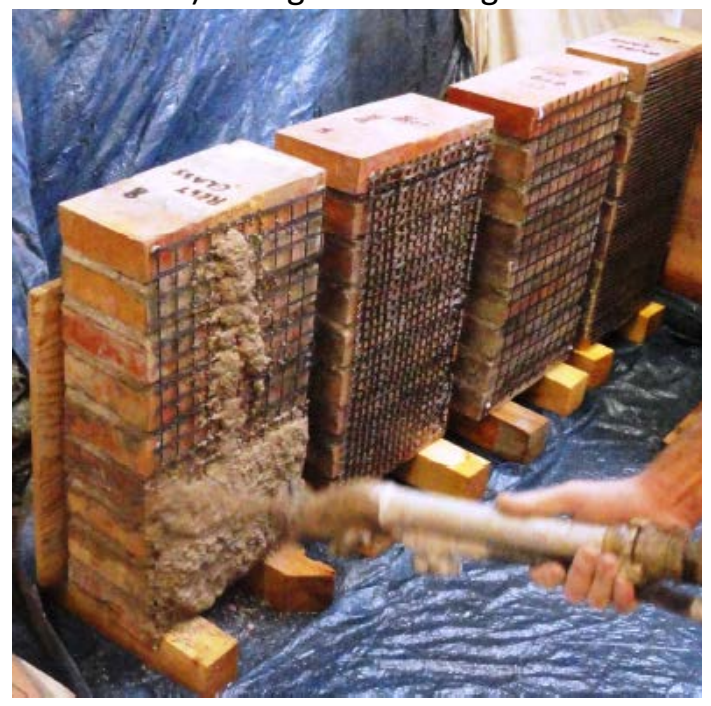

c) Spraying the mortar

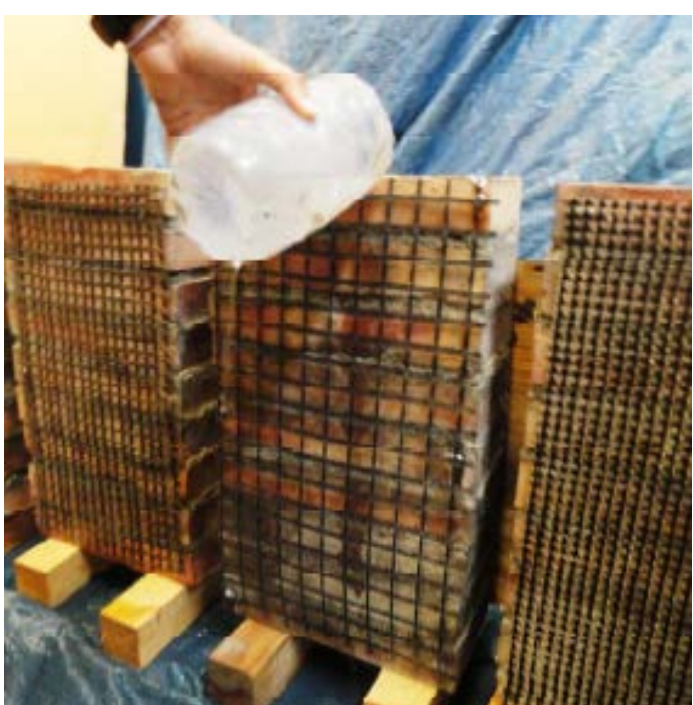

b) Wetting the specimen

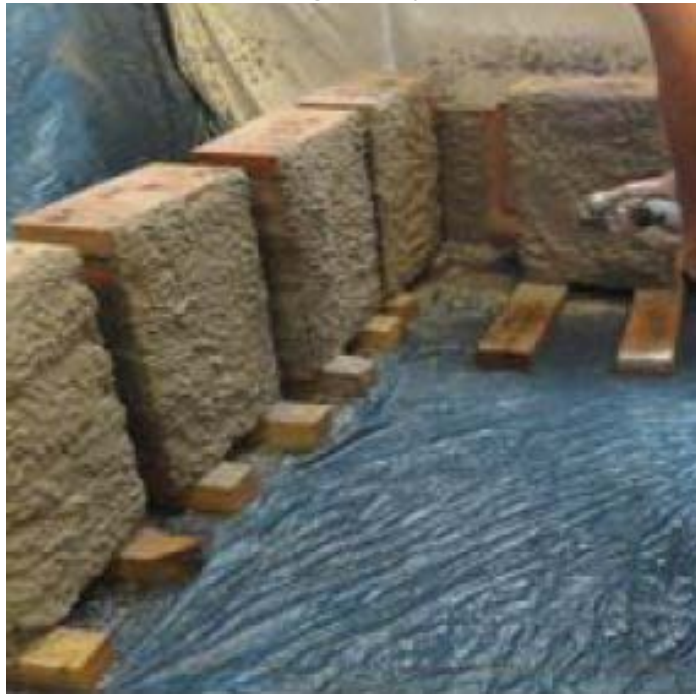

d) Strengthened specimens

Figure 3 TRSM application procedure 


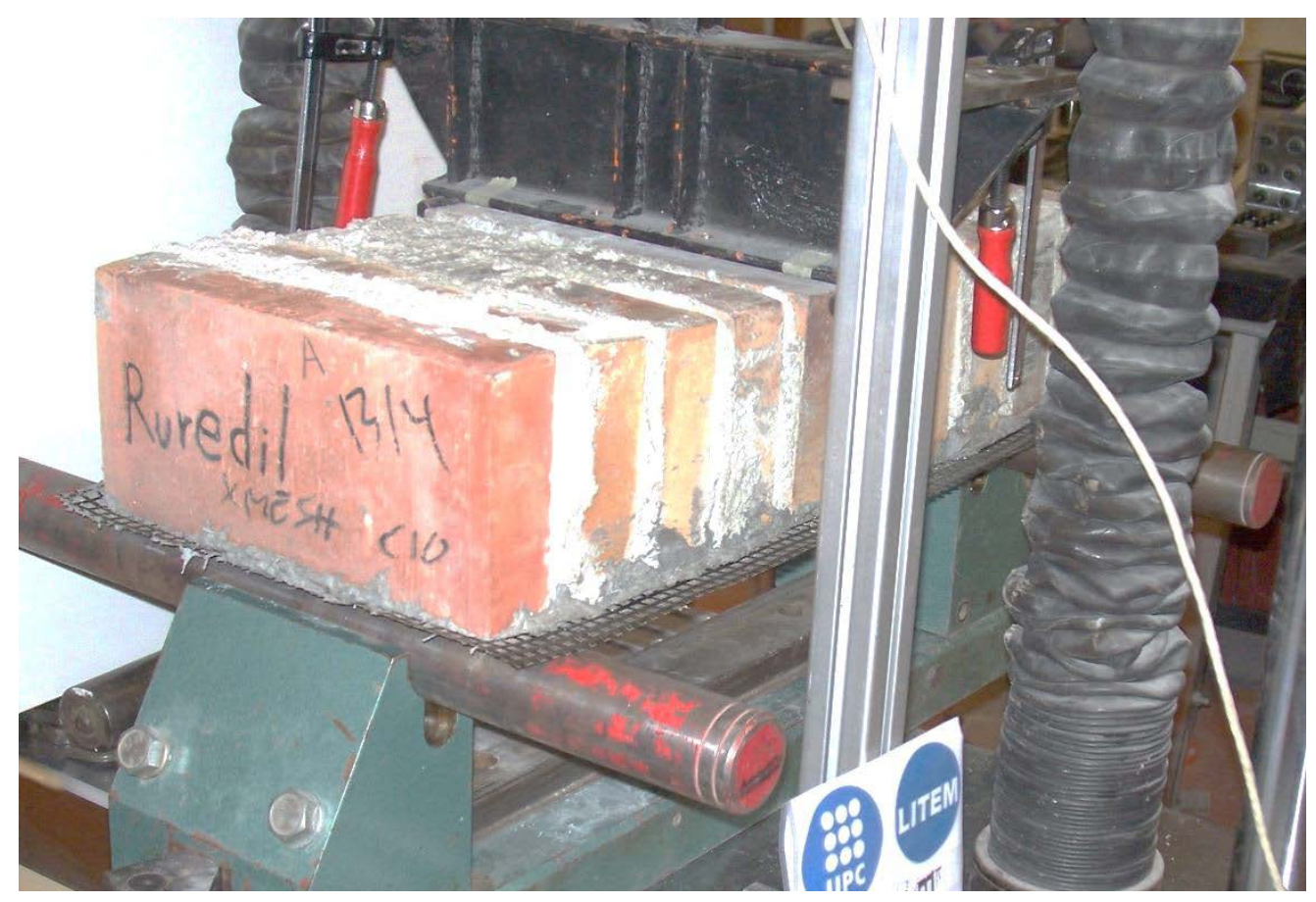

Figure 4 Test setup for the second group of the experimental campaign
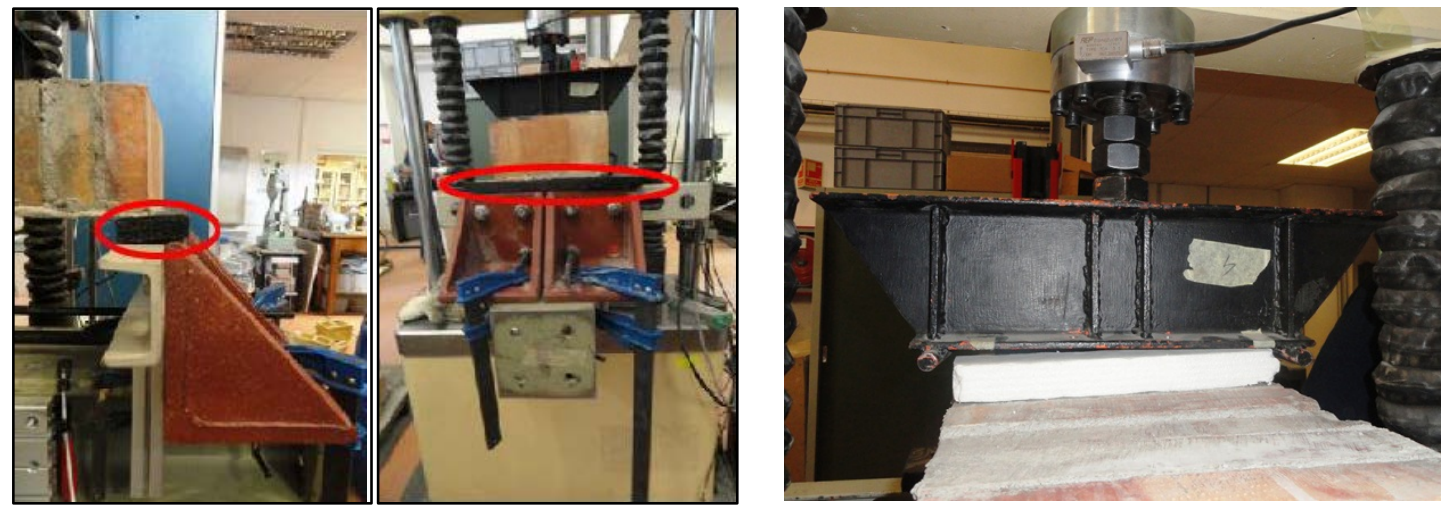

a) Elastomeric support

b) Thermocol sheet below the load application beam.

Figure 5 Test setup for the third group of the experimental campaign 


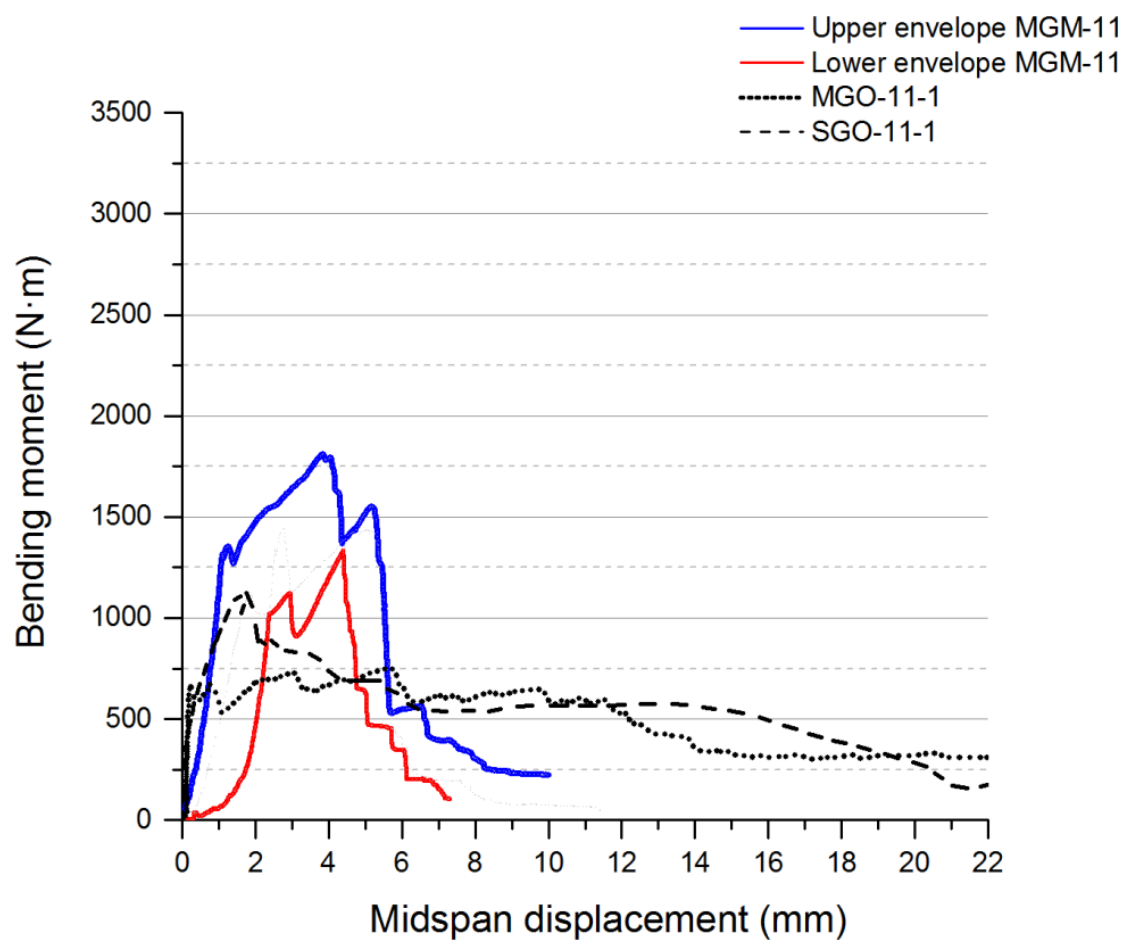

Figure 6 Bending moment - Mid-span displacement: upper and lower envelope for specimens of the MGM-11 series and data for the3rd group specimens reinforced with only one glassfibre sheet

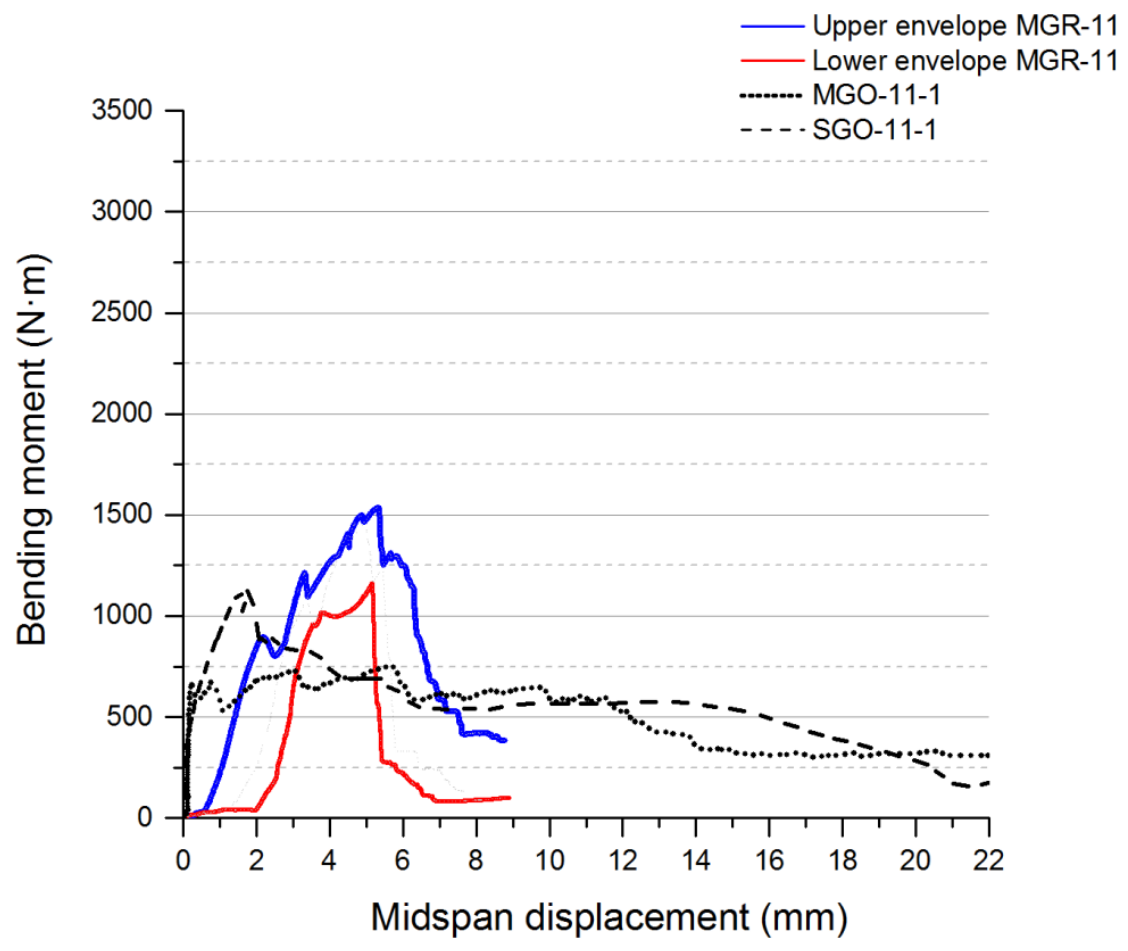

Figure 7 Bending moment - Mid-span displacement: upper and lower envelope for specimens of the MGR-11 series and data for the 3rd group specimens reinforced with only one glass fibre sheet 


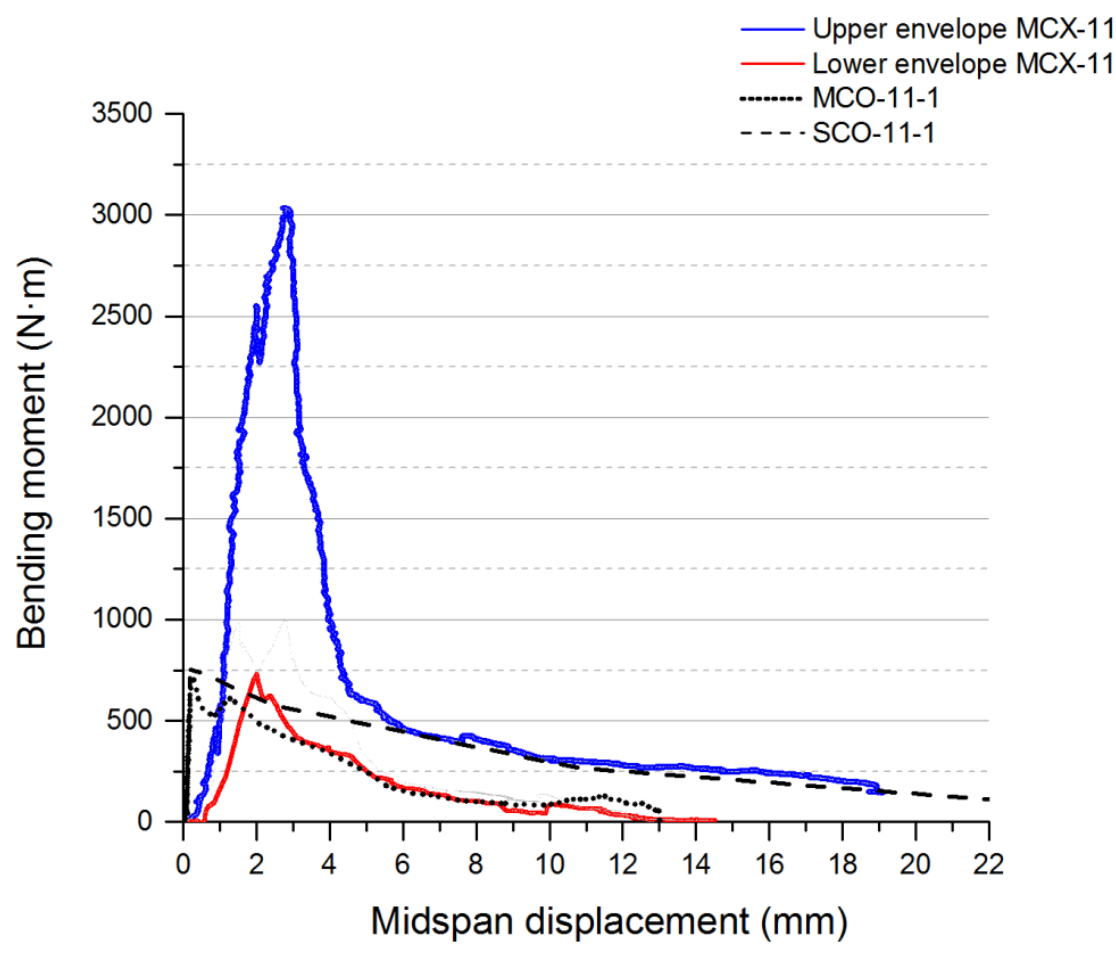

Figure 8 Bending moment - Mid-span displacement: upper and lower envelope for specimens of the MCX-11 series and data for the 3rd group specimens reinforced with only one carbon fibre sheet

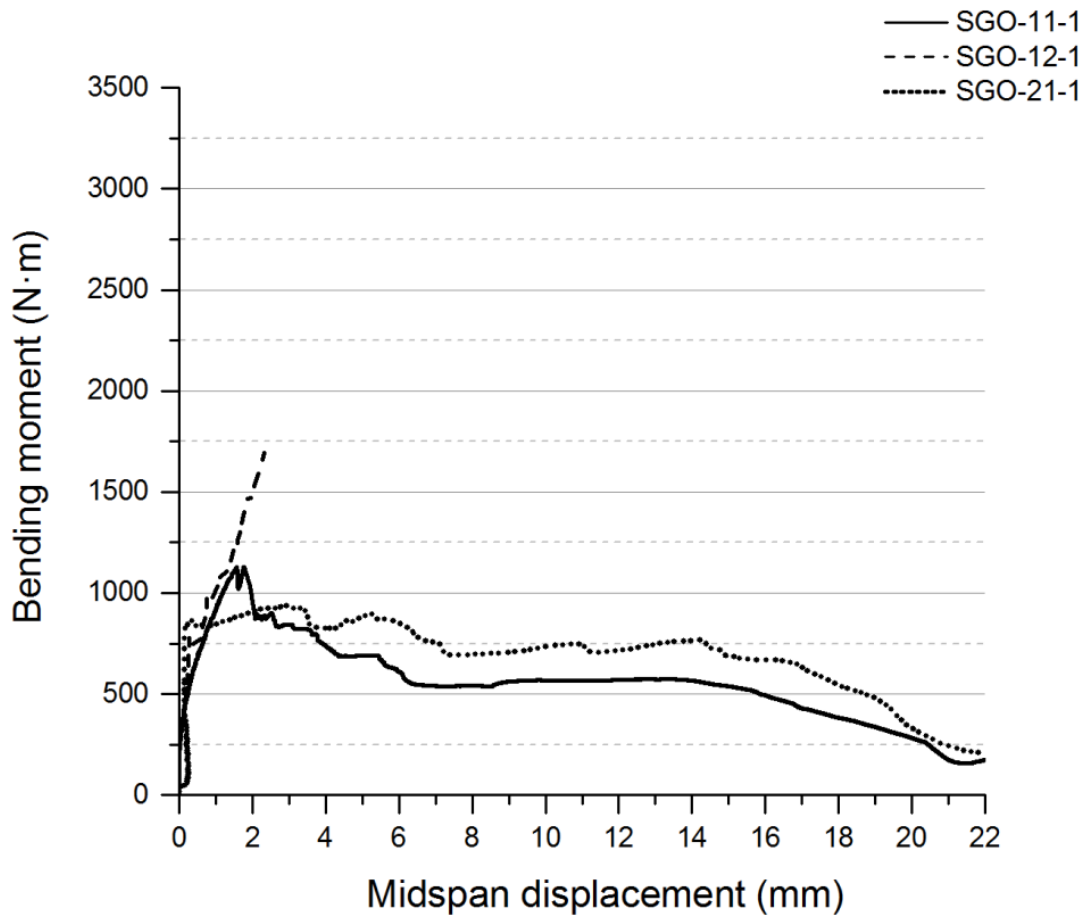

Figure 9 Bending moment - Mid-span displacement curves for 3rd group specimens strengthened with glass fibre grids 


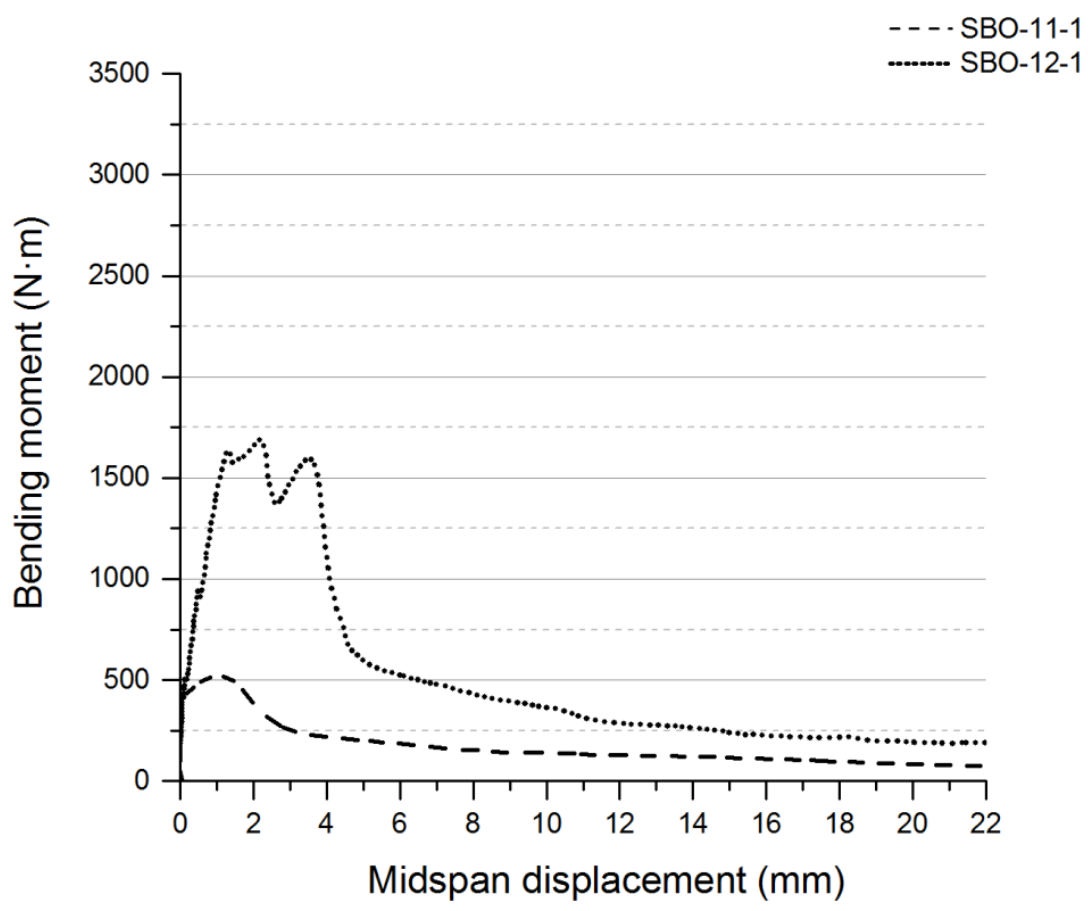

Figure 10 Bending moment - Mid-span displacement curves for 3rd group specimens strengthened with basalt fibre grids

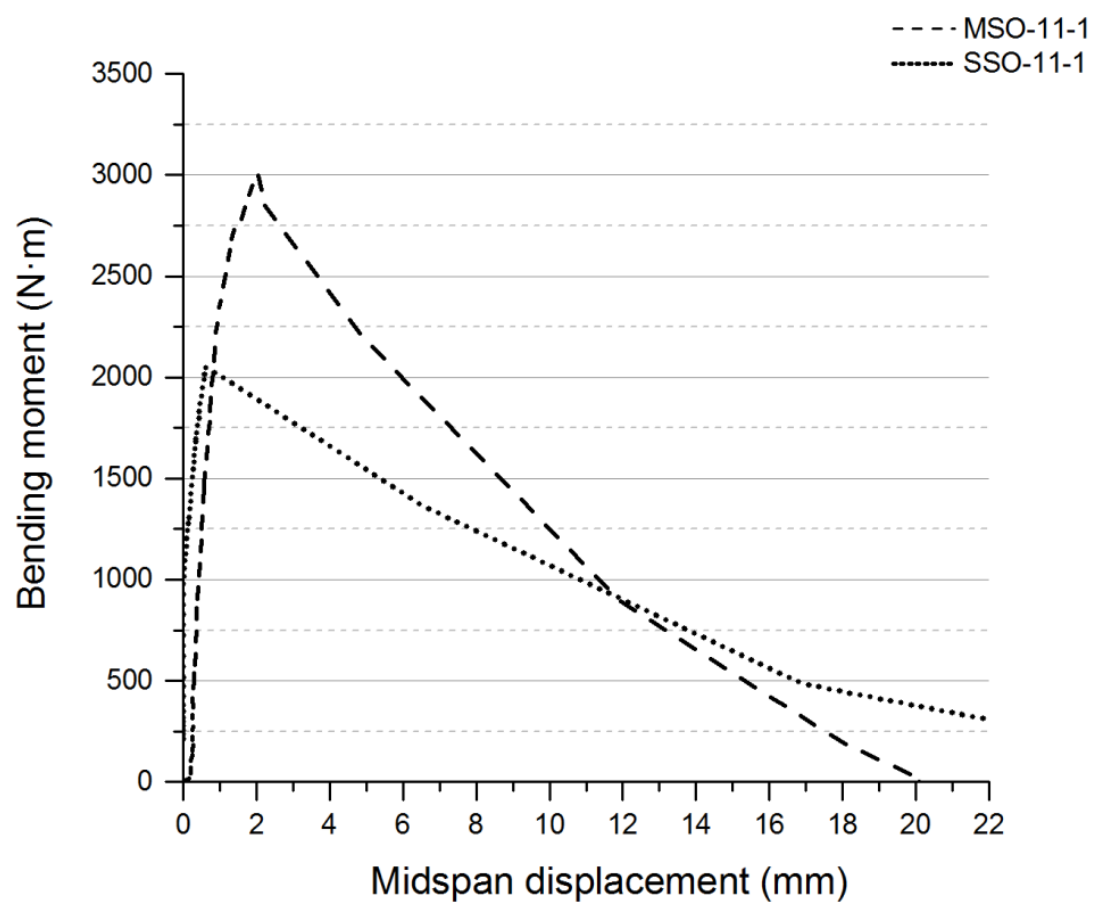

Figure 11 Bending moment - Mid-span displacement curves for 3rd group specimens strengthened with steel fibre 


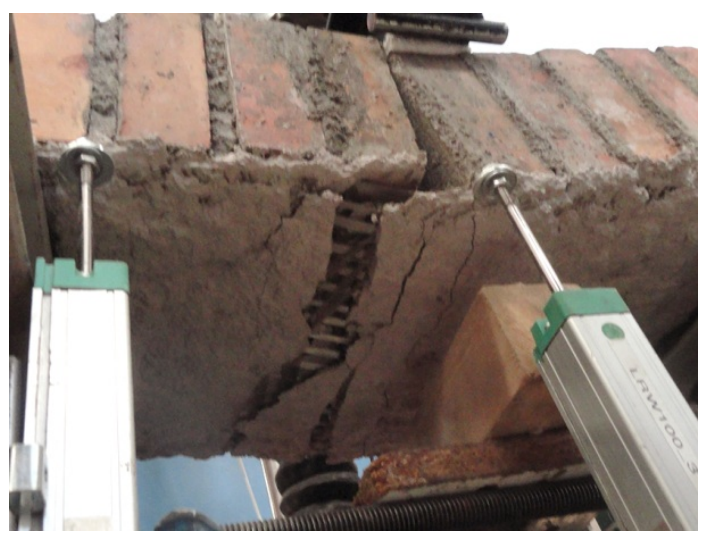

a) Flexure

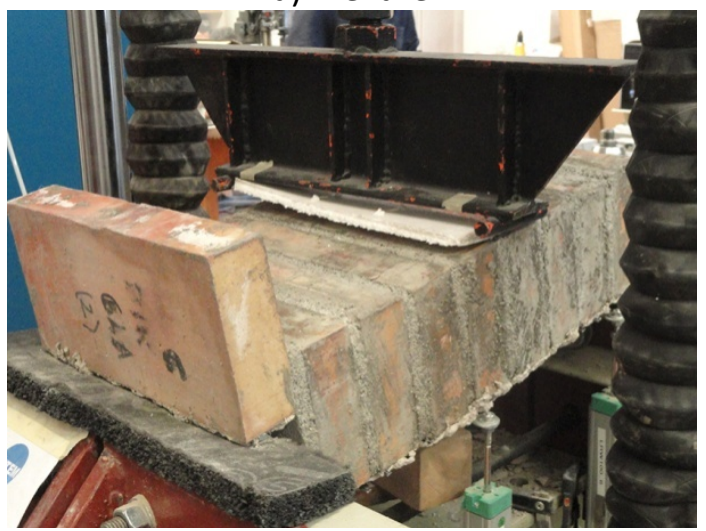

c) Shear

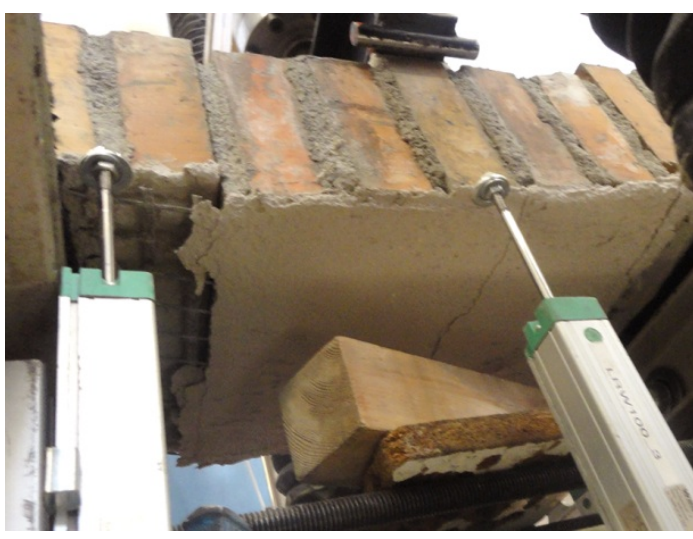

b) Flexure -> Shear

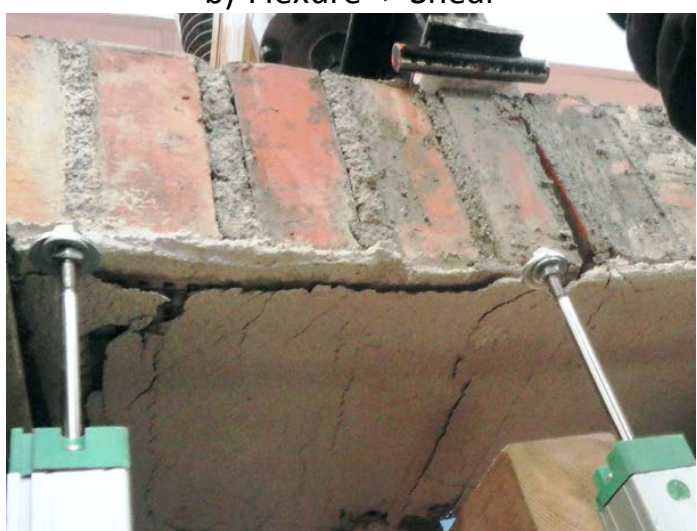

d) Debonding

Figure 12 Failure of the specimens tested

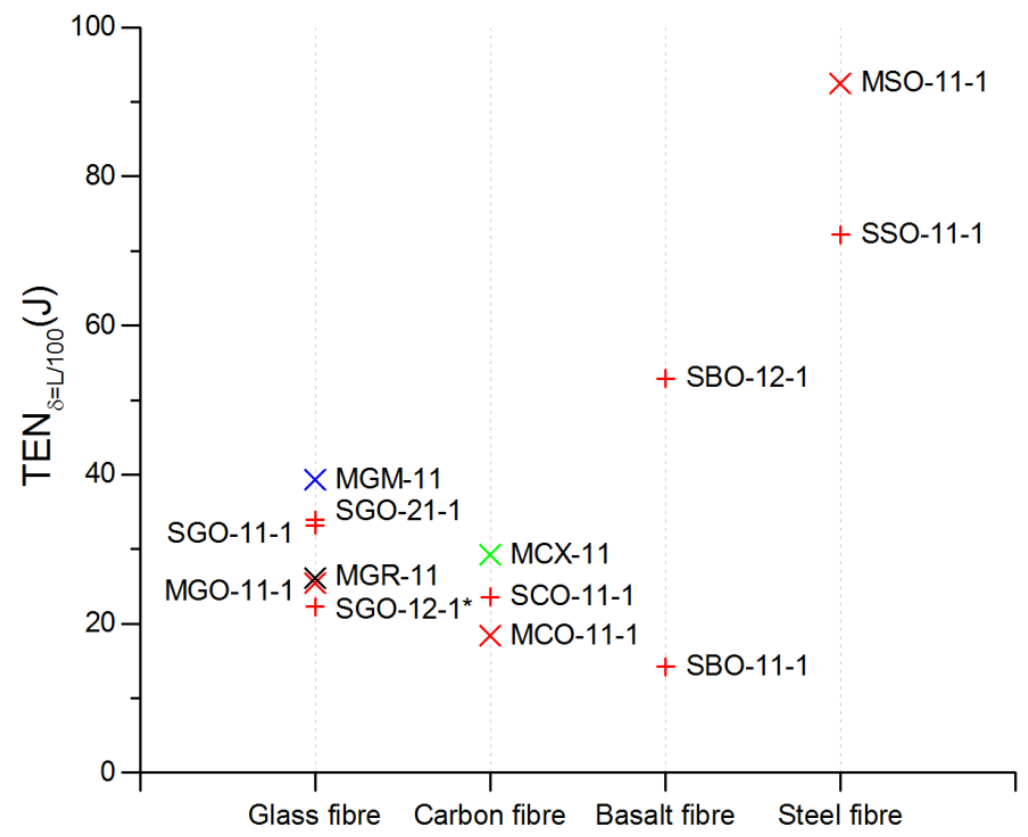

(*) Test did not reach L/100 mid-span displacement

Figure 13 Absorbed energy at L/100 mid-span displacement 